\title{
INSTITUIÇÕES DE ENSINO SUPERIOR COMUNITÁRIAS: QUESTÕES ATUAIS
}

\author{
COMMUNITARIAN INSTITUTIONS FOR HIGHER \\ EDUCATION: CURRENT ISSUES
}

\author{
Hélio Radke Bittencourt \\ Pontifícia Universidade Católica do Rio Grande do Sul - RS - Brasil \\ Alziro César de Morais Rodrigues \\ Pontifícia Universidade Católica do Rio Grande do Sul - RS - Brasil \\ Alam de Oliveira Casartelli \\ Pontifícia Universidade Católica do Rio Grande do Sul - RS - Brasil \\ Gustavo Inácio de Moraes \\ Pontifícia Universidade Católica do Rio Grande do Sul - RS - Brasil \\ Gabriela Ludwig Guerra \\ Pontifícia Universidade Católica do Rio Grande do Sul - RS - Brasil
}

\begin{abstract}
Resumo: Desde 2010, as instituições de ensino superior (IES) brasileiras comunitárias deixaram de figurar oficialmente nas sinopses e nos microdados do INEP sob essa denominação, com a extinção da categoria "comunitárias, confessionais e filantrópicas". Desde então, as IES brasileiras privadas são classificadas conforme sua natureza jurídica: com ou sem fins lucrativos. Essa realidade, contudo, foi modificada após a aprovação no Congresso Nacional da Lei $n^{\circ} 12.881$, sancionada em novembro de 2013, que dispõe, em especial, sobre a definição e as finalidades das instituições comunitárias, confirmando seu caráter de instituições não lucrativas, pertencentes à sociedade civil, e sua forma de organização em associações ou fundações (BRASIL, 2013). A recente expansão da rede federal e de IES com fins lucrativos tem afetado diretamente as até então denominadas comunitárias, que possuem características diferenciadas em relação às IES privadas com fins lucrativos, bem como às de ensino público. Neste artigo analisam-se dados e aspectos contemporâneos relacionados ao novo cenário da educação superior brasileira, com especial enfoque nas IES integrantes da Associação Brasileira de Universidades Comunitárias (ABRUC), tendo-se constatado melhor desempenho dessas na comparação com as IES privadas com fins lucrativos. Os resultados obtidos, aliados ao impacto regional das IES comunitárias, justificam a valorização dessas instituições que operam e contribuem para a consolidação dos cursos superiores no Brasil.
\end{abstract}

Palavras-chave: Universidades comunitárias, instituições de ensino superior, educação superior.

Abstract: Since 2010, the Brazilian communitarian institutions for higher education are not included officially under this designation in the INEP's microdata, with the extinction of the category "communitarian, religious and philanthropic". Since then, the Brazilian private's higher education institutions are classified according to their legal nature: for-profit or non-profit. Nevertheless, the new law 12.881 of 2013, enacted in November 2013, has changed this reality after the approval by the National Congress, establishing the definition and purpose of the Community institutions, and confirming, in particular, their characteristics of non-profit institutions belonging to civil society, and their organization into associations or foundations (BRAZIL, 2013). The recent expansion of the federal and for-profit higher education institutions has directly affected the so far called communitarian institutions, which present differentiated characteristics compared to forprofit private higher education institutions as well as public education. In this article, data and 
contemporary aspects related to the new scenario of Brazilian higher education are analyzed, with special focus on higher education institutions members of the Association of Community Universities (ABRUC), and were found better performance of these ones in comparison to the private for-profit higher education institutions. The obtained results, combined with the regional impact of the communitarian higher education institutions, justify the importance of these institutions to improve the consolidation of higher education in Brazil.

Keywords: Communitarian universities, higher education institutions, higher education.

\section{Introdução}

As instituições de ensino superior (IES) comunitárias têm sido diretamente atingidas pela expansão da rede federal e pelo aumento no número de instituições privadas com fins lucrativos. Esse cenário vem exigindo que as instituições comunitárias repensem sua atuação, passando a adotar uma nova postura no que compete à sua gestão estratégica, com maior preocupação acerca dos resultados de avaliações externas, dos investimentos em pesquisa e do reforço na captação e retenção de alunos. Esses aspectos impactam na oferta de cursos de diferentes níveis e na orientação dos eixos de pesquisa a serem fortalecidos.

O universo das IES comunitárias tende a se restringir em relação ao que tradicionalmente constituiu-se o âmbito de sua atuação. Conforme se altera o espaço de construção do saber, modificam-se os métodos de diálogo com a sociedade e, portanto, a visão de futuro se transforma.

As universidades comunitárias tiveram suas raízes nas escolas comunitárias implantadas no Brasil pelos imigrantes europeus, que encontraram um déficit na área educacional. Segundo Schmidt (2010) há dois fatores importantes na raiz desse fenômeno comunitário: 1) a herança cultural trazida da Europa, e 2) a necessidade de encontrar meios de suprir serviços indispensáveis à coletividade (educação, saúde, transportes, cultura). Possivelmente, a maior incidência de imigrantes europeus implicou uma maior concentração de instituições de ensino superior (IES) comunitárias na região Sul do Brasil.

Segundo a Associação Brasileira das Universidades Comunitárias (ABRUC), as universidades e centros universitários comunitários caracterizam-se pelo fato de não terem fins lucrativos, portanto os recursos gerados ou recebidos são integralmente aplicados em suas atividades. Além disso, não pertencem a investidores, sendo mantidas por comunidades, igrejas, congregações, etc., podendo ser confessionais ou não. As IES comunitárias têm, pois, um compromisso com a sociedade na qual estão inseridas, buscando atender às necessidades da comunidade. De acordo com Guareschi (2001), a marca da instituição comunitária não está em sua forma jurídica, mas na sua adequação às necessidades sociais da região na qual está inserida.

As universidades comunitárias não se enquadram nem no modelo público, tampouco no modelo privado (BITTAR, 1999). Elas representam um modelo alternativo, ou seja, não sendo pública, no sentido estatal, nem privada no sentido estrito, empresarial, elas são públicas não estatais (VANNUCHI, 2004). Diferentes discursos sobre a identidade comunitária foram conduzidos, especialmente diante da dicotomia público/privado. O caráter público e não estatal das instituições 
comunitárias vinha se afirmando, sendo, porém, insuficiente para impulsionar uma mobilização nacional na direção do estabelecimento de um marco legal específico do modelo comunitário até recentemente (SCHMIDT, 2010).

Essa realidade, contudo, foi modificada após a aprovação no Congresso Nacional da Lei 12.881, sancionada em novembro de 2013, que dispõe, em especial, sobre a definição e finalidades das instituições comunitárias, confirmando seu caráter de instituições não lucrativas, pertencentes à sociedade civil, e sua forma de organização em associações ou fundações (BRASIL, 2013).

A nova lei foi promulgada em momento oportuno, prevendo o repasse de recursos públicos às universidades enquadradas na definição, na forma dos editais tradicionalmente direcionados às universidades públicas, sobretudo porque adquire importância na perspectiva de maiores investimentos na educação brasileira, consequência da destinação prevista das receitas de exploração de petróleo, conforme Mário Cesar dos Santos, presidente da Acafe - Associação Catarinense de Fundações Educacionais (SANTOS, 2013).

Em certo sentido, a experiência brasileira guarda alguma relação com a experiência chilena. O processo de consolidação das universidades sem fins lucrativos no Chile ficou indefinido a partir da reforma universitária de 1981. Desde então, há universidades públicas, privadas e um terceiro grupo intermediário, que recebe recursos públicos, ainda que administradas privadamente, mas com reconhecimento de prestação de serviços públicos. Neste último rol duas são laicas e quatro vinculadas a hierarquias católicas (DONOSO DIAZ, 2005). Nesse contexto, pode-se afirmar algo perfeitamente aplicável ao Brasil: "(...) dificilmente se pode falar de um mercado homogêneo. Ao contrário, tratam-se de vários mercados heterogêneos, compostos por submercados, onde se relacionam e negociam diferentes forças e tensões" (DONOSO DIAZ, 2005, p.55).

Estudos e análises sobre o contexto da educação superior no Brasil ganham especial relevância. Este texto tem por objetivo apresentar uma análise do cenário da educação superior brasileira para as IES comunitárias, destacando aspectos de concorrência, ameaças e oportunidades, complementando a síntese de informações organizada por Thomé et al. (2011). O texto também procura debater o conceito de universidade comunitária, por vezes confundido com a categoria administrativa outrora adotada pelo MEC, e estabelecer um comparativo dos resultados de avaliação em larga escala das universidades comunitárias em relação às IES de outras categorias administrativas.

\section{Terminologia}

Segundo o INEP (2011), o número de instituições brasileiras de ensino superior totalizava 2.365. Em relação à denominação acadêmica, 190 eram universidades, 131 centros universitários, 2.004 faculdades e 40 eram centros ou institutos federais. Com respeito à categoria administrativa, a classificação adotada pelo Ministério da Educação (MEC) até 2008 distinguia duas categorias: IES particulares e IES comunitárias, confessionais e filantrópicas (CCF). A partir de 
2009, O MEC passou a considerar IES privadas comunitárias e IES privadas confessionais como duas organizações, aumentando para três o número de subdivisões das IES privadas (INEP, 2009). Os microdados do Censo da Educação Superior de 2009, no entanto, apresentavam inconsistências. A partir de 2010, a Sinopse da Educação Superior produzida pelo INEP (2010) passou a enquadrar todas as IES privadas em uma única categoria. No entanto, os microdados ainda permitem a diferenciação entre IES com ou sem fins lucrativos.

A falta de unanimidade na classificação das IES, até o advento da Lei $12.881 / 13$ não se constituía novidade. Historicamente, a classificação adotada pelo MEC não coincide com aquela adotada pela Associação Brasileira das Universidades Comunitárias (ABRUC), a qual, apesar de se referir a universidades, também inclui faculdades e centros universitários. A Tabela 1 resume a distribuição das IES brasileiras segundo as categorias administrativas, demonstrando maior presença de filiadas à $A B R U C$ dentre as universidades.

Tabela 1. Distribuição das IES brasileiras de acordo com a organização acadêmica, categorias administrativas e filiação à ABRUC

\begin{tabular}{l|c|c|c|c}
\hline $\begin{array}{c}\text { Organização } \\
\text { Acadêmica }\end{array}$ & $\begin{array}{c}\text { Públicas }+ \\
\text { Privadas }\end{array}$ & $\begin{array}{c}\text { Privada sem } \\
\text { fins lucrativos }\end{array}$ & $\begin{array}{c}\text { Comunitárias } \\
\text { filiadas à } \\
\text { ABRUC }\end{array}$ & $\begin{array}{c}\text { Proporção de privadas } \\
\text { sem fins lucrativos } \\
\text { filiadas à ABRUC }\end{array}$ \\
\hline Centros Universitários & 131 & 92 & 17 & $18,5 \%$ \\
Faculdades & 2004 & 921 & 4 & $0,4 \%$ \\
CEFET e IF & 40 & 0 & 0 & - \\
\hline Total & 2365 & 1082 & $58^{a}$ & $5,36 \%$ \\
\hline
\end{tabular}

Fonte: INEP, Sinopse Estatística 2010 e site: www.abruc.org.br (consulta em Nov/2012)

a Há três instituições filiadas à ABRUC consideradas como "categoria especial" e uma é "pública municipal" conforme categoria administrativa do MEC.

As 62 IES comunitárias que atualmente fazem parte da ABRUC tiveram seu credenciamento entre 1940 e 1999, tendo a maioria das instituições (55,2\%) sido credenciada nas décadas de 60 e 70, conforme mostra a Figura 1. Oportuno notar que a despeito do recente crescimento no número de IES no Brasil, as comunitárias consolidaram-se em um cenário diverso do atual e em um período em que o papel da educação superior era discutido e transformado. A esse respeito, deve-se destacar que as IES comunitárias são criadas no momento em que se debatia o papel do ensino superior com base no decreto-lei 53 de 1966, e da reforma universitária de 1968, frutos de uma estruturação do ensino superior brasileiro, que de maneira geral tinha como inspiração o modelo norte-americano (TRINDADE, 2007). Tal reforma, também se insere em um quadro de modernização econômica e social do Brasil. Logo, as IES comunitárias tiveram importante papel na própria consolidação do novo modelo universitário que se almejava, com todas as suas eventuais virtudes e defeitos. 


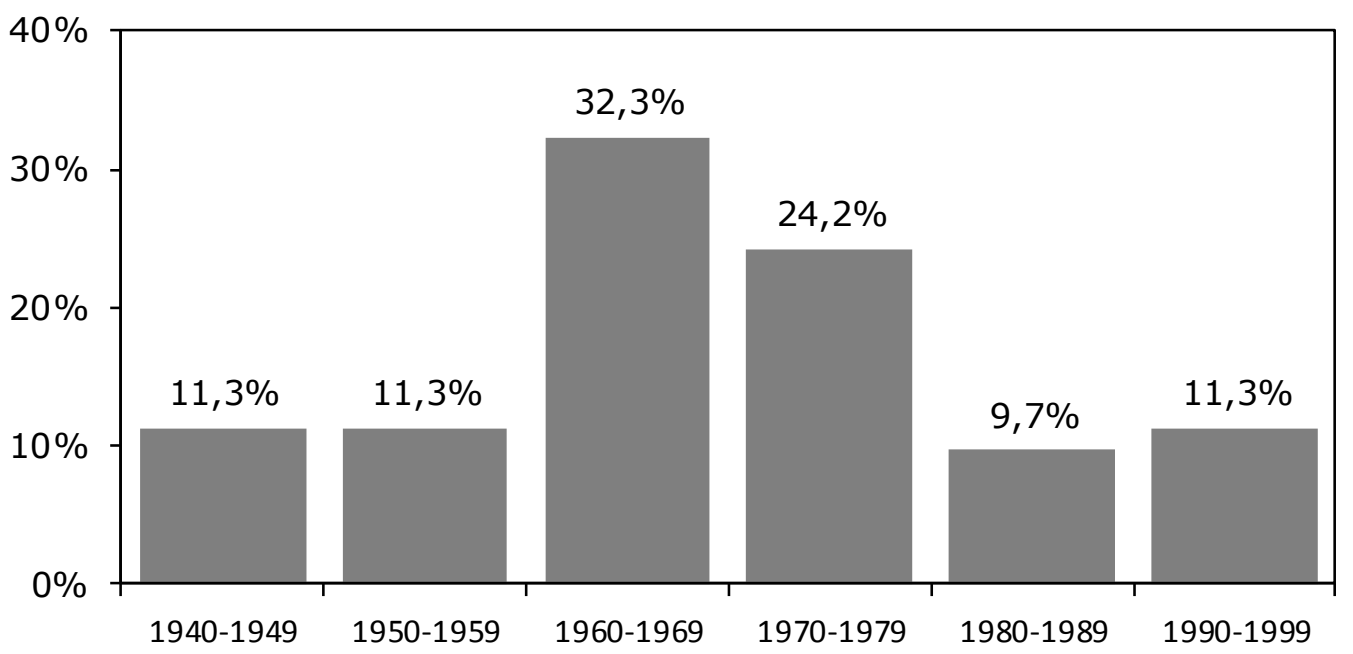

Figura 1. Distribuição das IES comunitárias conforme o período de credenciamento Fonte: Sistema e-MEC (emec.mec.gov.br). Consulta em julho/2012.

\section{Cenário atual}

O número de IES brasileiras cresceu em ritmo acelerado entre 2001 e 2006, tendo no setor privado ocorrido um crescimento de $67 \%$, ao passo que, no mesmo período, registrou-se um aumento de 36\% no número de IES públicas. Entre 2006 e 2008, tanto o setor público como o privado viveram um período de estabilidade, seguido de um crescimento até o ano de 2010 (Figura 2). De 2008 a 2010, agregaram-se 84 novas IES privadas e 42 novas IES públicas.

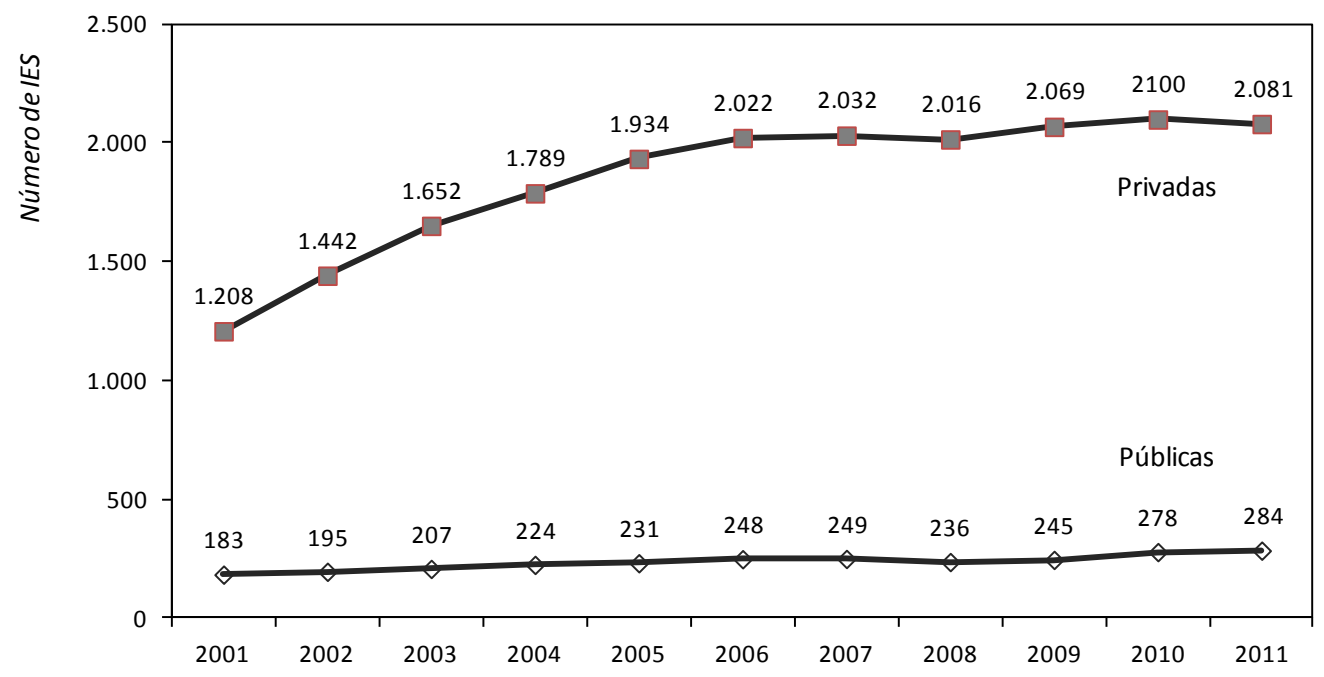

Figura 2. Evolução no número de IES por categoria administrativa Fonte: Sinopses Estatísticas 2001-2011, MEC/INEP. 
Os dados de 2011 revelaram decréscimo de 19 IES privadas em relação ao ano anterior, contrastando com um aumento de seis novas IES públicas. A expansão da rede federal de IES foi responsável pelo aumento de vagas no setor público. No período de 2001 a 2011, o número de vagas oferecidas por instituições federais mais do que dobrou. Na rede privada, o aumento no número de vagas ofertadas se deu principalmente entre as IES com fins lucrativos, que quase quadruplicaram a oferta nesse período. Utilizando critério de classificação do MEC/INEP, a oferta de vagas por instituições comunitárias cresceu apenas 34\% entre 2001 e 2008 (INEP, 2010) ${ }^{1}$.

As Tabelas 2 e 3 apresentam dados e indicadores extraídos dos microdados do Censo da Educação Superior de 2011 (INEP, 2011), distinguidas por categoria administrativa. As 62 IES que compõem o estrato das comunitárias estão apartadas das demais categorias.

Tabela 2. Números relacionados à educação superior brasileira (presencial) por categoria administrativa e grupo ABRUC

\begin{tabular}{|c|c|c|c|c|c|c|}
\hline $\begin{array}{c}\text { Categoria } \\
\text { Administrativa }\end{array}$ & $\begin{array}{c}\text { Número } \\
\text { de IES }\end{array}$ & Matrículas & Concluintes & Ingressantes & Vagas & Inscritos \\
\hline Pública federal & 103 & 927.086 & 98.383 & 282.007 & 270.121 & 3.657 .540 \\
\hline Pública estadual & 110 & 548.202 & 76.980 & 138.990 & 152.121 & 1.390 .625 \\
\hline $\begin{array}{l}\text { Comunitárias - } \\
\text { ABRUC }\end{array}$ & 62 & 640.665 & 101.942 & 184.168 & 249.504 & 462.547 \\
\hline $\begin{array}{l}\text { Privada com fins } \\
\text { lucrativos }\end{array}$ & 972 & 1.734 .700 & 274.783 & 598.098 & 1.202 .145 & 1.807 .765 \\
\hline $\begin{array}{l}\text { Privada sem fins } \\
\text { lucrativos }\end{array}$ & 1047 & 1.803 .555 & 297.820 & 684.812 & 1.301 .834 & 1.848 .110 \\
\hline Pública municipal & 67 & 92.554 & 15.253 & 27.023 & 52.946 & 71.658 \\
\hline Total & 2361 & 5.746 .762 & 865.161 & 1.915 .098 & 3.228 .671 & 9.166 .587 \\
\hline
\end{tabular}

Fonte: Microdados da Educação Superior, 2011. MEC/INEP.

Tabela 3. Indicadores institucionais da educação superior brasileira (presencial) por categoria administrativa e grupo ABRUC

\begin{tabular}{lccccc}
\hline \multicolumn{1}{c}{$\begin{array}{c}\text { Categoria } \\
\text { Administrativa }\end{array}$} & $\begin{array}{c}\text { Tamanho médio da } \\
\text { graduação } \\
\text { (matrículas) }\end{array}$ & $\begin{array}{c}\text { Fração } \\
\text { das } \\
\text { matrículas }\end{array}$ & $\begin{array}{c}\text { Inscritos } \\
\text { Vaga }\end{array}$ & $\begin{array}{c}\text { Vagas não } \\
\text { preenchidas }\end{array}$ & $\begin{array}{c}\text { Ingressante / } \\
\text { Concluinte }\end{array}$ \\
\hline Pública federal & 9.001 & $16,13 \%$ & 13,54 & $4,40 \%$ & 2,87 \\
Pública estadual & 4.984 & $9,54 \%$ & 9,14 & $8,63 \%$ & 1,81 \\
Comunitárias - ABRUC & 10.333 & $11,15 \%$ & 1,85 & $26,19 \%$ & 1,81 \\
Privada com fins & 1.785 & $30,19 \%$ & 1,50 & $50,25 \%$ & 2,18 \\
lucrativos & 1.723 & $31,38 \%$ & 1,42 & $47,40 \%$ & 2,30 \\
Privada sem fins & 1.381 & $1,61 \%$ & 1,35 & $48,96 \%$ & 1,77 \\
lucrativos & - & $100,00 \%$ & 2,84 & $40,68 \%$ & 2,21 \\
Pública municipal & & & & & \\
\hline Total & & & & &
\end{tabular}

Fonte: Microdados da Educação Superior, 2011. MEC/INEP.

\footnotetext{
1 Não houve como utilizar os dados de 2009 e 2010 visto que o critério de classificação nas sinopses do MEC/INEP foi alterado.
} 
Os dados de 2011 indicam que o segmento de instituições comunitárias é formado essencialmente por instituições de grande porte, sendo responsável por $11,15 \%$ do total de matrículas presenciais em território nacional. Nesse ano, registrou-se um percentual de $26,19 \%$ de vagas não preenchidas nessa categoria, cifra que corresponde praticamente à metade da taxa registrada para as demais IES privadas.

A procura pelos cursos das IES comunitárias registrou 1,85 inscritos por vaga, conforme Tabela 3, número bastante inferior às instituições públicas federais e estaduais, mas, por outro lado, superior às demais instituições de caráter privado.

Contudo, o cenário do momento é insuficiente para se compreender a dinâmica recente desfavorável às instituições comunitárias. Enquanto as universidades públicas, estimuladas pelo Programa de Apoio a Planos de Reestruturação e Expansão das Universidades Federais (REUNI), alcançam outro patamar para o número de matrículas, sobretudo no período entre 2005 e 2010, e as universidades privadas mais do que dobram a quantidade de alunos na última década, as universidades comunitárias registram crescimento lento. Os números da Tabela 4 mostram essa evolução.

Tabela 4. Evolução das Matrículas nas Universidades Brasileiras - por Categoria Administrativa, em Anos Selecionados - em mil alunos

\begin{tabular}{|c|c|c|c|c|c|c|c|c|}
\hline \multirow{2}{*}{$\begin{array}{c}\text { Categoria } \\
\text { Administrativa }\end{array}$} & \multicolumn{7}{|c|}{ Ano } & \multirow[b]{2}{*}{ Var. } \\
\hline & 2004 & 2005 & 2007 & 2008 & 2009 & 2010 & 2011 & \\
\hline Comunitárias - ABRUC & $570,8 \quad 658,6$ & 665,8 & 644,9 & 637,9 & 629,6 & 638,1 & 640,7 & $12,2 \%$ \\
\hline IES Públicas * & $904,51.107,61$ & $1.134,0^{\prime}$ & $1.195,81$ & $1.234,9$ & $1.331,7$ & $1.456,21$ & $1.567,8$ & $73,3 \%$ \\
\hline IES Privadas * & $\begin{array}{r}1.554,2.395,02 \\
5\end{array}$ & $2.650,53$ & $3.038,93$ & $3.205,03$ & $3.154,5$ & $3.354,73$ & $3.538,3$ & $\begin{array}{r}127,6 \\
\%\end{array}$ \\
\hline $\begin{array}{l}\text { Participação \% das } \\
\text { Comunitárias - ABRUC }\end{array}$ & $18,8 \% \quad 15,8 \%$ & $15,0 \%$ & $13,2 \%$ & $12,6 \%$ & $12,3 \%$ & $11,7 \%$ & $11,1 \%$ & - \\
\hline
\end{tabular}

* Não incluem as 62 IES comunitárias filiadas à ABRUC

Fonte: Microdados da Educação Superior, 2011. MEC/INEP.

Assim, na primeira década do século $X X I$, a participação de matrículas nas IES Comunitárias decresce de quase 19\% para 11,1\%. Deve-se acrescentar que enquanto a evolução no número de matrículas é permanente nas universidades públicas e privadas, entre as comunitárias há decréscimo entre os anos 2004 e 2009. Em outras palavras, é possível inferir que a atração exercida pelas universidades no período recente não alcançou as comunitárias e evidencia, em primeiro plano, a segmentação das IES no Brasil. Outro aspecto interessante que sobressai a partir de uma análise das IES brasileiras é a dificuldade de posicionamento das comunitárias nesse contexto.

Do ponto de vista de sua distribuição geográfica, observa-se uma maior concentração nas regiões Sul e Sudeste do país, conforme mostram as Figuras 3 e 4, com apenas dois estados brasileiros (SP e RS) concentrando mais da metade das 
instituições comunitárias brasileiras. Os estados que ocupam as cinco primeiras posições (Figura 4) encontram-se nas regiões Sul ou Sudeste, reunindo 83,9\% do total de IES.

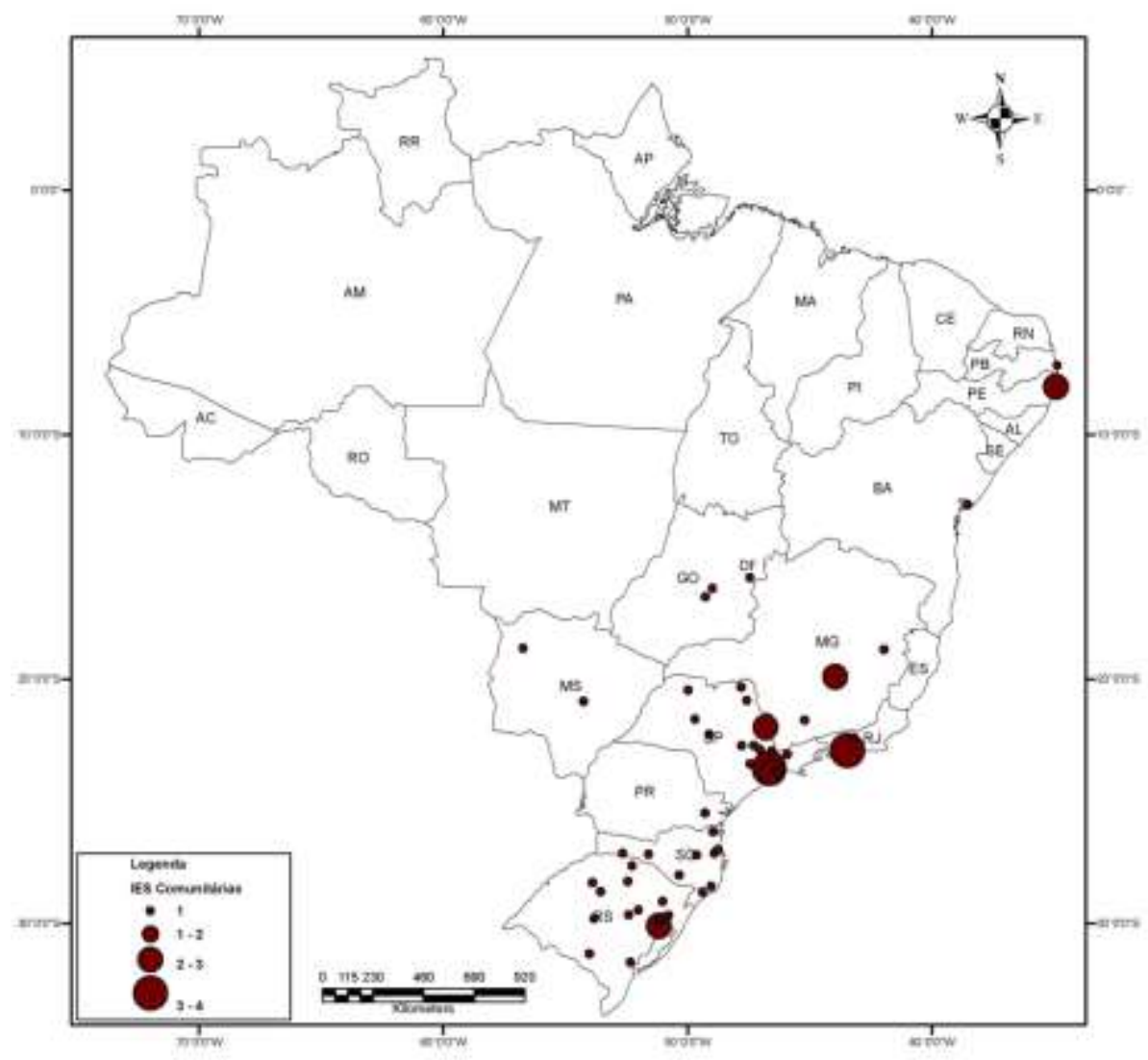

Figura 3. Mapa da distribuição das IES comunitárias brasileiras, filiadas à $A B R U C$ Fonte: Elaborado pelo Laboratório LTIG da PUCRS com base em dados da Associação Brasileira de Universidades Comunitárias (ABRUC) e do Instituto Brasileiro de Geografia e Estatística (IBGE).

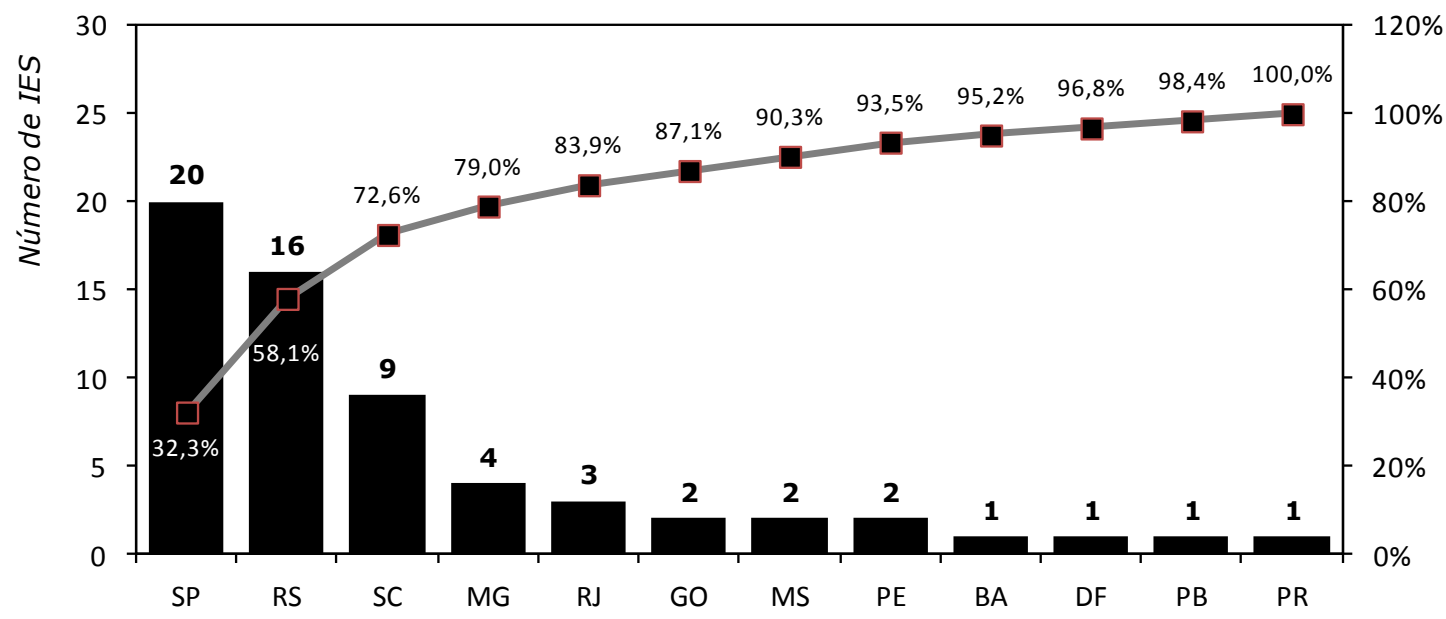

Figura 4. Distribuição do número de IES comunitárias por Unidade da Federação Fonte: Associação Brasileira de Universidades Comunitárias (ABRUC) 
Esse padrão de distribuição geográfica pode estar associado ao nível de qualidade de vida que as localidades servidas pelas comunitárias desfrutam (Tabela 5). Dos 100 municípios brasileiros com melhor qualidade de vida, considerando-se o Índice de Desenvolvimento Humano (IDH), 22 deles contam com IES comunitárias (PNUD, 2003; ABRUC 2012). Quando se relaciona tal comportamento com o IDH Educação ${ }^{2}$, reforça-se a importância das instituições comunitárias para o incremento do Índice de Desenvolvimento Humano dos municípios.

Tabela 5. Frequência da Classificação dos Municípios ${ }^{3}$ com IES Comunitárias - IDH

\begin{tabular}{c|cc}
\hline \multirow{2}{*}{ Classificação } & \multicolumn{2}{|c}{ Presença de Comunitárias } \\
\cline { 2 - 3 } & Municípios IDH & Municípios IDH Educação \\
\hline $1^{\circ}$ até $40^{\circ}$ & 9 & 9 \\
$41^{\circ}$ até $100^{\circ}$ & 13 & 10 \\
$101^{\circ}$ até $500^{\circ}$ & 22 & 23 \\
$501^{\circ}$ até $1000^{\circ}$ & 5 & 7 \\
$1001^{\circ}$ até $1291^{\circ}$ & 3 & 3 \\
\hline
\end{tabular}

Fonte: Elaborado a partir de ABRUC (2012) e PNUD (2003)

Suscita inquietação que, embora o número de matrículas seja um item valorizado na construção do IDH-Educação, a presença de IES comunitárias poderia contribuir ainda mais para melhorar o desempenho dos municípios brasileiros neste índice em particular. Isso demonstra, correlacionado à Tabela 3, que os $25,3 \%$ de vagas não preenchidas nas IES comunitárias podem contribuir decisivamente para o desenvolvimento humano dos municípios onde estão instaladas.

Em relação à distribuição das matrículas por turno, percebe-se que, desde 2001, há um aumento paulatino na fração de matrículas no turno da noite entre as IES privadas (Figura 5) ${ }^{4}$. A título de comparação, nesse mesmo período, o percentual de matrículas no turno noturno em IES públicas não ultrapassou $38 \%$ (INEP, 2011).

\footnotetext{
${ }^{2} \mathrm{O}$ IDH-Educação é formado a partir de dois índices: taxa de analfabetismo e a proporção de matriculados em qualquer curso regular e que tenham idades entre 7 e 22 anos. (PNUD, 2003)

${ }^{3}$ Universo de 5.507 municípios avaliados.

${ }^{4}$ Os dados de 2009 não se encontram disponíveis e, devido à nova classificação das IES adotada pelo INEP após 2008, não foi possível apresentar os dados separadamente para o grupo das comunitárias.
} 


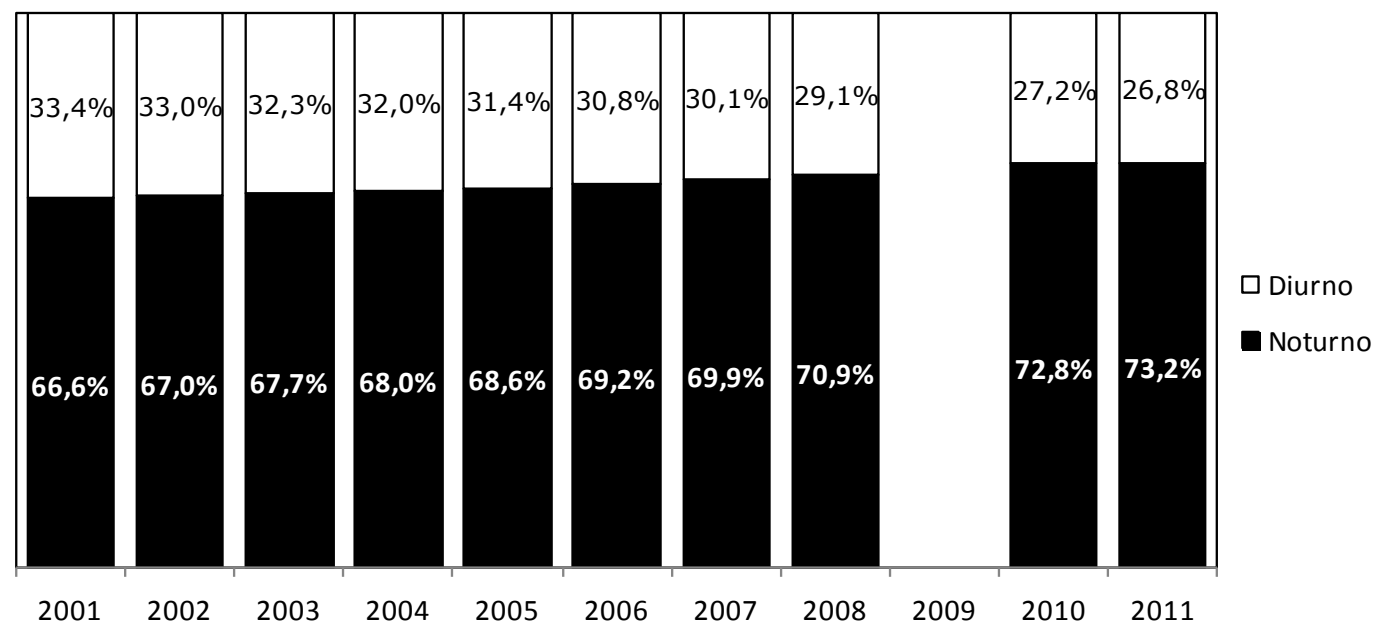

Figura 5. Evolução da distribuição de matrículas por turno em instituições privadas Fonte: Sinopses Estatísticas da Educação Superior, 2001-2011. MEC/INEP.

Outro aspecto que merece ser discutido é a proporção de matrículas por área do conhecimento, que varia substancialmente entre as categorias administrativas, embora haja um conjunto de áreas comuns que figuram em todas elas. A Tabela 6 apresenta as áreas com maior número de matrículas por segmento.

Tabela 6. Os dez cursos com maior número de matrículas por categoria administrativa

\begin{tabular}{|c|c|c|c|c|c|}
\hline \multirow{2}{*}{ Área } & \multicolumn{2}{|c|}{ Públicas } & \multirow{2}{*}{ Área } & \multicolumn{2}{|c|}{ Privada com fins } \\
\hline & Matrículas & $\begin{array}{c}\% \\
\text { Acum. }\end{array}$ & & Matrículas & $\begin{array}{c}\% \\
\text { Acum. }\end{array}$ \\
\hline $\begin{array}{l}\text { Formação de professor de } \\
\text { matérias específicas }\end{array}$ & 300.410 & $20,7 \%$ & $\begin{array}{l}\text { Gerenciamento e } \\
\text { administração }\end{array}$ & 377.162 & $23,6 \%$ \\
\hline Ciências da educação & 93.574 & $27,2 \%$ & Direito & 254.011 & $39,5 \%$ \\
\hline Gerenciamento e administração & 84.592 & $33,0 \%$ & $\begin{array}{l}\text { Enfermagem e atenção } \\
\text { primária (assistência básica) }\end{array}$ & 93.940 & $45,3 \%$ \\
\hline Direito & 68.572 & $37,7 \%$ & Ciências da educação & 87.533 & $50,8 \%$ \\
\hline Produção agrícola e pecuária & 58.202 & $41,7 \%$ & Contabilidade e tributação & 74.492 & $55,5 \%$ \\
\hline $\begin{array}{l}\text { Formação de professor de } \\
\text { disciplinas profissionais }\end{array}$ & 54.785 & $45,5 \%$ & Terapia e reabilitação & 61.115 & $59,3 \%$ \\
\hline $\begin{array}{l}\text { Engenharia e profissões de } \\
\text { engenharia } \\
\text { (cursos gerais) }\end{array}$ & 44.656 & $48,6 \%$ & $\begin{array}{l}\text { Processamento da } \\
\text { informação }\end{array}$ & 53.471 & $62,6 \%$ \\
\hline Contabilidade e tributação & 41.229 & $51,4 \%$ & Marketing e publicidade & 49.358 & $65,7 \%$ \\
\hline Medicina & 40.854 & $54,2 \%$ & $\begin{array}{l}\text { Engenharia e profissões de } \\
\text { engenharia (cursos gerais) }\end{array}$ & 46.910 & $68,7 \%$ \\
\hline Engenharia civil e de construção & 35.794 & $56,7 \%$ & $\begin{array}{l}\text { Formação de professor de } \\
\text { matérias específicas }\end{array}$ & 46.228 & $71,5 \%$ \\
\hline$\ldots$ & $\cdots$ & & & $\ldots$ & \\
\hline Total de matrículas & 1.450 .807 & & Total de matrículas & 1.599 .228 & \\
\hline
\end{tabular}


Continuação

\begin{tabular}{|c|c|c|c|c|c|}
\hline \multirow{2}{*}{ Área } & \multicolumn{2}{|c|}{ Privada sem fins } & \multirow{2}{*}{ Área } & \multicolumn{2}{|c|}{$\begin{array}{c}\text { Comunitárias - } \\
\text { ABRUC }\end{array}$} \\
\hline & Matrículas & $\begin{array}{c}\% \\
\text { Acum. }\end{array}$ & & Matrículas & $\begin{array}{c}\% \\
\text { Acum. }\end{array}$ \\
\hline Gerenciamento e administração & 356.371 & $20,2 \%$ & Direito & 115.189 & $18,1 \%$ \\
\hline Direito & 256.675 & $34,8 \%$ & $\begin{array}{l}\text { Gerenciamento e } \\
\text { administração }\end{array}$ & 92.831 & $32,6 \%$ \\
\hline Ciências da educação & 98.326 & $40,4 \%$ & $\begin{array}{l}\text { Formação de professor de } \\
\text { matérias específicas }\end{array}$ & 36.124 & $38,3 \%$ \\
\hline $\begin{array}{l}\text { Enfermagem e atenção primária } \\
\text { (assistência básica) }\end{array}$ & 97.140 & $45,9 \%$ & Psicologia & 26.552 & $42,4 \%$ \\
\hline Contabilidade e tributação & 83.872 & $50,7 \%$ & Terapia e reabilitação & 25.852 & $46,5 \%$ \\
\hline $\begin{array}{l}\text { Formação de professor de } \\
\text { matérias específicas }\end{array}$ & 78.087 & $55,1 \%$ & $\begin{array}{l}\text { Engenharia e profissões de } \\
\text { engenharia (cursos gerais) }\end{array}$ & 25.484 & $50,5 \%$ \\
\hline Terapia e reabilitação & 62.409 & $58,7 \%$ & Contabilidade e tributação & 24.635 & $54,3 \%$ \\
\hline $\begin{array}{l}\text { Formação de professor de } \\
\text { disciplinas profissionais } \\
\text { Engenharia e profissões de }\end{array}$ & 56.057 & $61,8 \%$ & $\begin{array}{l}\text { Enfermagem e atenção } \\
\text { primária (assistência básica) }\end{array}$ & 19.729 & $57,4 \%$ \\
\hline $\begin{array}{l}\text { engenharia } \\
\text { (cursos gerais) }\end{array}$ & 52.962 & $64,8 \%$ & Ciências da educação & 18.330 & $60,3 \%$ \\
\hline Processamento da informação & 48.387 & $67,6 \%$ & Jornalismo e reportagem & 18.049 & $63,1 \%$ \\
\hline Total de matrículas & 1.760 .961 & & Total de matrículas & 638.124 & \\
\hline
\end{tabular}

Fonte: Microdados da Educação Superior, 2010. MEC/INEP.

A área de formação de professores (licenciaturas) ocupa a primeira posição dentre as instituições públicas, com $20,7 \%$ do total de matrículas. Essa mesma área situa-se na $10^{a}$ colocação nas IES privadas com fins lucrativos; $8^{a}$ colocação nas privadas sem fins lucrativos e $3^{a}$ posição dentre as comunitárias. A área de Direito figura nas primeiras posições em todas as categorias, mas ocupa a primeira posição apenas nas IES comunitárias.

Em todas as categorias, as áreas de Gerenciamento e Administração e Direito estão entre as quatro primeiras posições. As áreas de Psicologia e Jornalismo e Reportagem constam apenas na lista das Comunitárias. Reforça-se assim a impressão de que as IES, segundo suas categorias administrativas, possuem diferentes distribuições de matrículas por área e, portanto, com contribuições distintas ao sistema universitário brasileiro.

Portanto, a partir do conjunto de indicadores apresentados nessa seção estabelece-se uma caracterização dos segmentos que atuam dentro do ensino universitário brasileiro. Em especial, a especificidade do posicionamento das IES comunitárias frente ao crescimento das IES privadas com fins lucrativos e IES públicas. Na próxima seção esta caracterização será aprofundada a partir da avaliação de indicadores referentes aos instrumentos de avaliação disponíveis no ensino da graduação e da pós-graduação. 


\section{As IES Comunitárias e o SINAES}

Em 2004 foi instituído o Sistema Nacional de Avaliação da Educação Superior (SINAES) na forma da lei federal 10.861, com o objetivo de avaliar a qualidade, intervir em instituições problemáticas e permitir comparações de desempenho. O SINAES contempla três tipos de avaliações: avaliação institucional, avaliação de cursos e avaliação do desempenho dos estudantes, ainda que haja uma tendência de supervalorização do Exame Nacional de Desempenho de Estudantes (Enade) devido à maciça repercussão na mídia (RISTOFF; GIOLO, 2006; BITTENCOURT et al., 2010).

Decorrente do Enade, outro indicador de visibilidade significativa é o Conceito Preliminar de Cursos (CPC), derivado de um conjunto de variáveis, onde o Enade tem um peso maior. Aspectos como infraestrutura, titulação docente, tempo de dedicação dos professores e organização pedagógica são considerados também na composição desse indicador. As IES que obtêm resultados de avaliação de CPC 1 e 2 recebem, em caráter obrigatório, a visita de avaliadores in loco, que estabelecem um conceito de curso (CC), que é fundamental para avaliar a qualidade dos cursos com CPC baixos.

Do ponto de vista institucional, no entanto, o indicador mais representativo do SINAES é o IGC (Índice Geral de Cursos), que é um indicador institucional que pretende expressar, de maneira sintetizada, a qualidade dos cursos de graduação e pós-graduação de uma IES. A importância do IGC está justamente na medição da qualidade do ensino superior tanto na graduação como na pós-graduação de forma conjunta.

Além do IGC, O MEC estabelece também o Conceito Institucional (CI), resultante de avaliações in loco realizadas a cada ciclo avaliativo. $\mathrm{O} \mathrm{Cl}$ passou a ser referência para atestar a qualidade da IES, podendo ser consultado no sistema $e$ Mec. A Tabela 7 apresenta a distribuição dos $\mathrm{Cls}$ institucionais conforme a categoria administrativa. Das 2.378 IES que constam na Tabela 2, 848 não têm Cl e, por esse motivo, foram omitidas da Tabela 7.

Tabela 7. Distribuição do Conceito Institucional (Cl) por faixas segundo a categoria administrativa

\begin{tabular}{|c|c|c|c|c|c|c|c|}
\hline \multirow{2}{*}{$\begin{array}{c}\text { Categoria } \\
\text { Administrativa }\end{array}$} & \multicolumn{5}{|c|}{ Conceito Institucional - Cl } & \multirow[b]{2}{*}{ Média } & \multirow[b]{2}{*}{ Tota } \\
\hline & 1 & 2 & 3 & 4 & 5 & & \\
\hline Pública Federal & $0,0 \%$ & $4,3 \%$ & $44,7 \%$ & $42,6 \%$ & $8,5 \%$ & 3,556 & 47 \\
\hline Pública Estadual & $0,0 \%$ & $0,0 \%$ & $100,0 \%$ & $0,0 \%$ & $0,0 \%$ & 3,000 & 1 \\
\hline Comunitárias - ABRUC & $0,0 \%$ & $0,0 \%$ & $38,0 \%$ & $48,0 \%$ & $14,0 \%$ & 3,760 & 50 \\
\hline Privada com fins & $0,1 \%$ & $5,2 \%$ & $71,3 \%$ & $21,1 \%$ & $2,2 \%$ & 3,198 & 677 \\
\hline Privada sem fins & $0,1 \%$ & $5,9 \%$ & $70,5 \%$ & $20,3 \%$ & $3,2 \%$ & 3,206 & 749 \\
\hline Pública Municipal & $0,0 \%$ & $33,3 \%$ & $66,7 \%$ & $0,0 \%$ & $0,0 \%$ & 2,661 & 6 \\
\hline Total & $0,1 \%$ & $5,4 \%$ & $69,0 \%$ & $22,2 \%$ & $3,3 \%$ & 3,331 & 1530 \\
\hline
\end{tabular}

Fonte: Sistema e-MEC. Consulta em Junho/2012. 
A categorias das comunitárias é aquela que concentra a maior proporção de IES com $\mathrm{Cl} \geq 4$. Das 50 IES que têm $\mathrm{Cl}$, nenhuma apresenta conceito inferior a três. Em relação ao conceito IGC, a situação muda (Tabela 8 ). Apenas 12,9\% das comunitárias apresentam IGC $\geq 4$, sendo que a maioria das IES comunitárias apresenta $\mathrm{IGC}=3$. Entre todas as categorias, as comunitárias apresentam o menor percentual de conceitos considerados baixos pelo MEC (IGC $\leq 2)$.

Tabela 8. Distribuição do IGC por faixas segundo a categoria administrativa

\begin{tabular}{lccccccc}
\hline \multicolumn{1}{c}{$\begin{array}{c}\text { Categoria } \\
\text { Administrativa }\end{array}$} & 1 & 2 & 3 & 4 & 5 & Média & Total \\
\cline { 2 - 6 } Pública Federal & $0,0 \%$ & $2,2 \%$ & $35,6 \%$ & $50,0 \%$ & $12,2 \%$ & 3,722 & 90 \\
Pública Estadual & $1,6 \%$ & $9,8 \%$ & $54,1 \%$ & $27,9 \%$ & $6,6 \%$ & 3,281 & 61 \\
Comunitárias - ABRUC & $0,0 \%$ & $1,6 \%$ & $\mathbf{8 5 , 5 \%}$ & $12,9 \%$ & $0,0 \%$ & 3,113 & 62 \\
Privada com fins & $0,7 \%$ & $42,3 \%$ & $53,1 \%$ & $3,5 \%$ & $0,4 \%$ & 2,786 & 723 \\
Privada sem fins & $0,2 \%$ & $39,1 \%$ & $55,6 \%$ & $4,1 \%$ & $1,0 \%$ & 2,684 & 836 \\
Pública Municipal & $1,9 \%$ & $58,5 \%$ & $34,0 \%$ & $3,8 \%$ & $1,9 \%$ & 2,456 & 53 \\
\hline Total & $0,5 \%$ & $36,9 \%$ & $54,0 \%$ & $7,2 \%$ & $1,5 \%$ & 2,723 & 1825 \\
\hline
\end{tabular}

Fonte: Sistema e-MEC. Consulta em junho/2012.

Seguindo na análise do IGC, a Figura 6 apresenta um gráfico do tipo boxplot para o IGC contínuo. As Comunitárias apresentam o segundo IGC mediano mais alto e uma variabilidade relativamente pequena, ocupando uma posição intermediária entre as demais instituições privadas e as públicas federais.

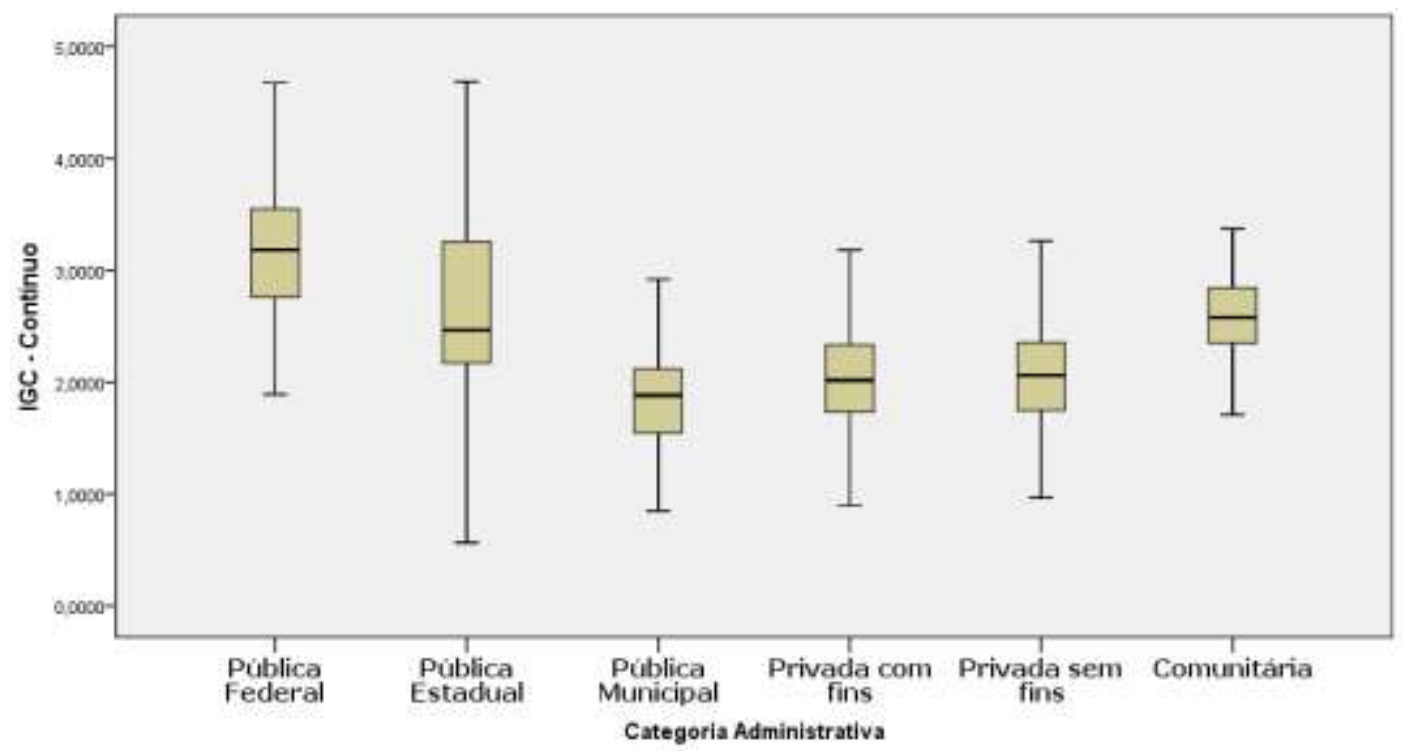

Figura 6. Boxplot para IGC contínuo por categoria administrativa, isolando as IES comunitárias

Fonte: MEC/INEP. Resultados do IGC 2010. 
De maneira resumida, o IGC é formado por três componentes ( $G, M, D)$, os quais resumem os conceitos médios dos cursos de graduação, mestrado e doutorado de uma IES. O componente G corresponde à média dos CPCS, ponderada pelo número de matrículas. Até o ano de 2010, o CPC correspondia a uma média ponderada de oito indicadores (INEP, 2010):

1. Proporção de professores com título de doutor;

2. Proporção de professores com título igual ou superior ao de mestre;

3. Proporção de professores com regime de dedicação parcial ou total;

4. Avaliação da infraestrutura (equipamentos) pelos alunos;

5. Avaliação da organização didático-pedagógica pelos alunos;

6. Nota dos alunos concluintes no Enade;

7. Nota dos alunos ingressantes no Enade;

8. Nota do Indicador de Diferença de Desempenho - IDD.

Os componentes $M$ e D do IGC são calculados a partir dos conceitos da avaliação trienal da Capes. Para melhor entendimento do cálculo do IGC e da composição dos Conceitos Preliminares de Curso (CPC), sugerem-se consultar as notas técnicas do INEP (2010a, 2010b), bem como os trabalhos de Bittencourt, Casartelli e Rodrigues (2009) e Bittencourt et al. (2010).

Em 2008 e 2009, os dados da decomposição do CPC foram disponibilizados pelo INEP, possibilitando avaliar as notas em cada um dos oito componentes nas diferentes categorias de IES. A Figura 7 apresenta esses resultados, revelando que as instituições públicas apresentaram, em média, melhor desempenho nas provas do Enade, tanto para ingressantes como para concluintes.

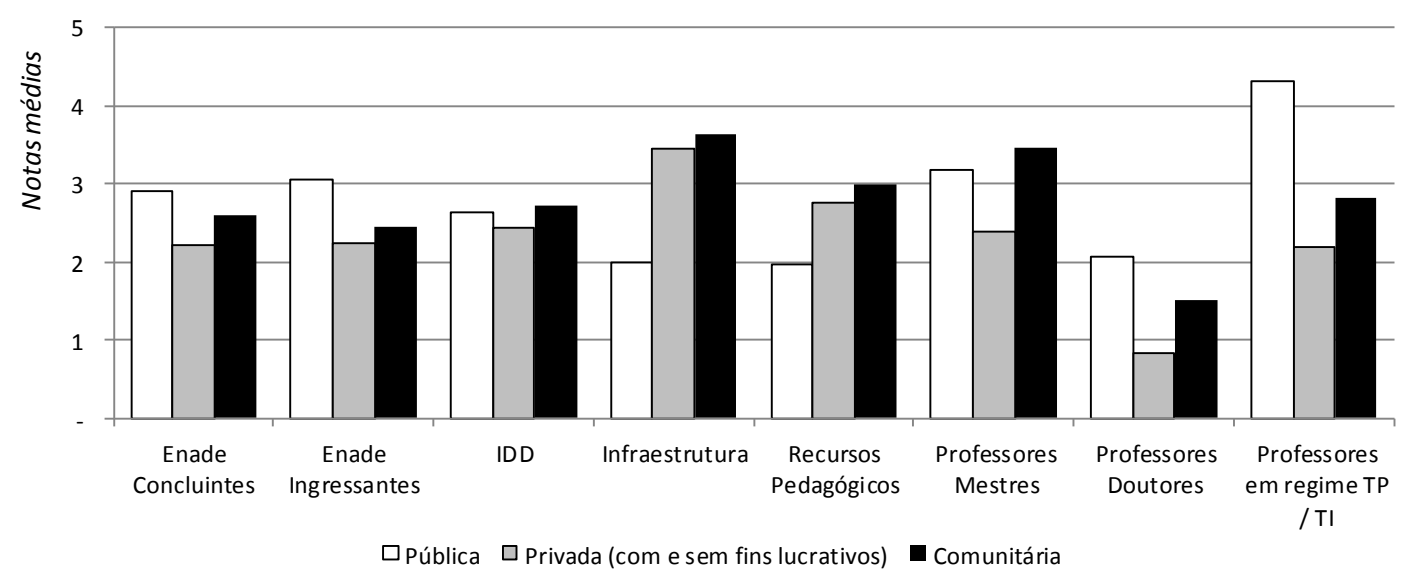

Figura 7. Notas médias dos componentes do CPC conforme categoria administrativa

Fonte: MEC/INEP. Resultados do IGC 2009.

Como no IGC, o grupo das comunitárias ocupa uma posição intermediária entre as demais IES privadas e o grupo das públicas. Já no IDD, há um equilíbrio entre as três categorias, com as comunitárias apresentando um desempenho médio levemente superior às demais. 
Nos quesitos relacionados à infraestrutura e à organização didáticopedagógica, o grupo de IES comunitárias apresentou médias muito superiores às instituições públicas e levemente superiores às demais IES privadas. Esse resultado reforça os achados de Bittencourt et al. (2010), que concluíram que a infraestrutura e a organização didático-pedagógica, juntamente com o IDD, são indicadores favoráveis às universidades privadas.

Em relação ao corpo docente, as IES comunitárias apresentam o melhor desempenho na nota referente à proporção de professores com, no mínimo, titulação de Mestre, mas, quando a titulação mínima considerada é o Doutorado, a média cai cerca de dois pontos, ficando abaixo das IES públicas. A maior diferença entre IES públicas e privadas (incluindo comunitárias ou não) dá-se na proporção de professores em regime de tempo parcial ou integral. Sabe-se que a figura do professor horista praticamente inexiste em IES públicas, de forma que quase a totalidade do corpo docente pode ser considerada em tempo parcial ou integral. Isso contribui para que a nota média deste componente seja próxima de 5 em IES públicas.

\subsection{As universidades comunitárias e a Resolução n 03/2010 do CNE}

A Resolução No 3 do Conselho Nacional de Educação (MEC/CNE, 2010), regulamenta e dispõe sobre as normas para credenciamento e recredenciamento de universidades do Sistema Federal de Ensino. O artigo $8^{\circ}$ lista as seguintes condições indispensáveis para o recredenciamento como universidade:

I - um terço do corpo docente com titulação de mestrado ou doutorado;

II - um terço do corpo docente em regime de tempo parcial ou integral;

III - Conceito Institucional $(\mathrm{Cl})$ maior ou igual a três;

IV - Índice Geral de Cursos (IGC) maior ou igual a três;

V - oferta regular de, no mínimo, $60 \%$ dos cursos de graduação reconhecidos ou em processo de reconhecimento;

VI - oferta regular de, pelo menos, quatro cursos de mestrado e dois de doutorado reconhecidos;

VII - compatibilidade com o Plano de Desenvolvimento Institucional (PDI).

A Figura 8 apresenta a proporção de universidades comunitárias que satisfazem os incisos I, II, III, IV e VI da resolução do CNE. Apenas 38,5\% das 39 universidades comunitárias atendem a todos os requisitos necessários para recredenciamento com a mesma denominação acadêmica. 


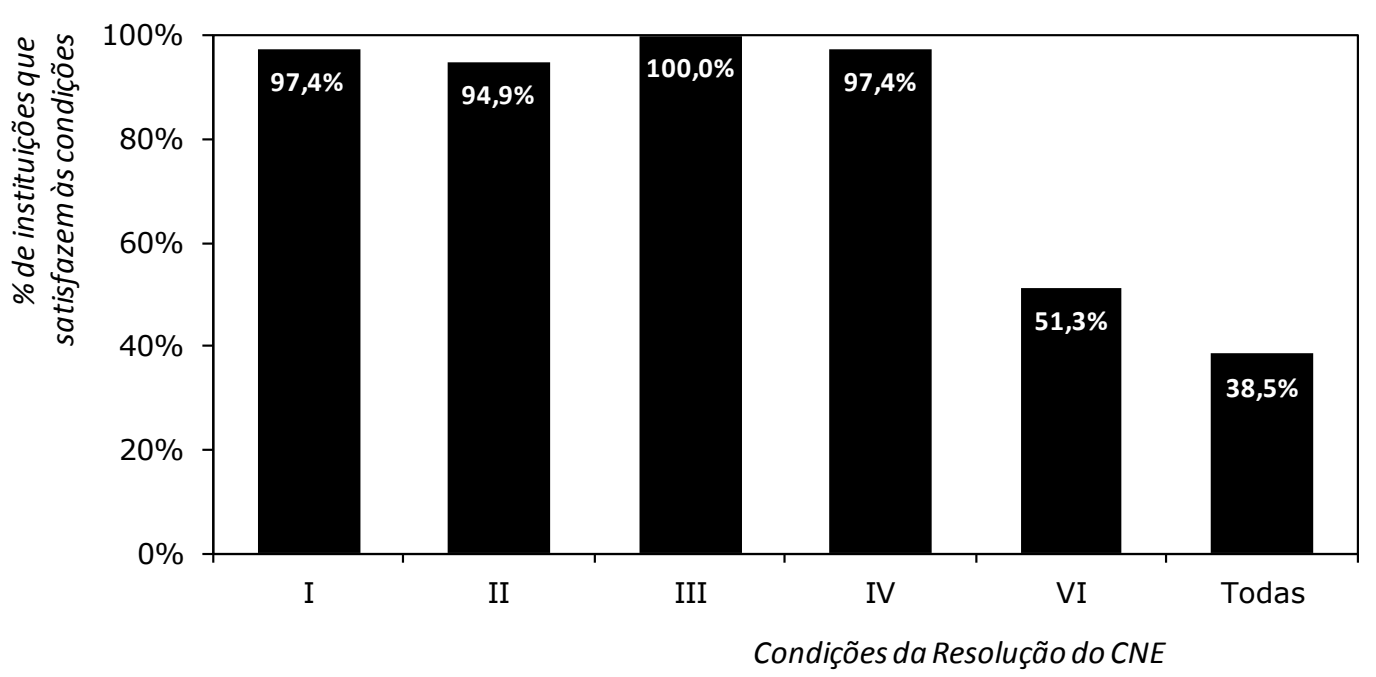

Figura 8. Proporção de universidades comunitárias que atendem às condições para recredenciamento

Fontes: MEC/INEP, Microdados do Censo da Educação Superior 2011. Resultados do IGC 2010. CAPES.

Dos cinco critérios analisados, a oferta de quatro cursos de mestrado e dois de doutorado é, destacadamente, aquele que apresenta o maior desafio para as universidades comunitárias. Dessas instituições, oito $(20,5 \%)$ não contam com cursos de doutorado. A avaliação e o desempenho dos cursos de pós-graduação stricto sensu nas universidades comunitárias passa a ser analisado na seção seguinte.

\section{As Universidades e a pós-graduação stricto sensu}

As matrículas na pós-graduação stricto sensu crescem em âmbito nacional influenciadas sobretudo pela rede pública federal. Enquanto esse indicador cresce a taxas decrescentes nas IES comunitárias e privadas, nas instituições federais o crescimento assume um padrão diferente, registrando taxas crescentes. As instituições públicas estaduais, que representam a segunda força em âmbito nacional, registram uma taxa de crescimento em torno de 5\% ao ano desde 2005. A Figura 9 apresenta a evolução no século XXI das matrículas por categoria administrativa, evidenciando o progresso distinto. 


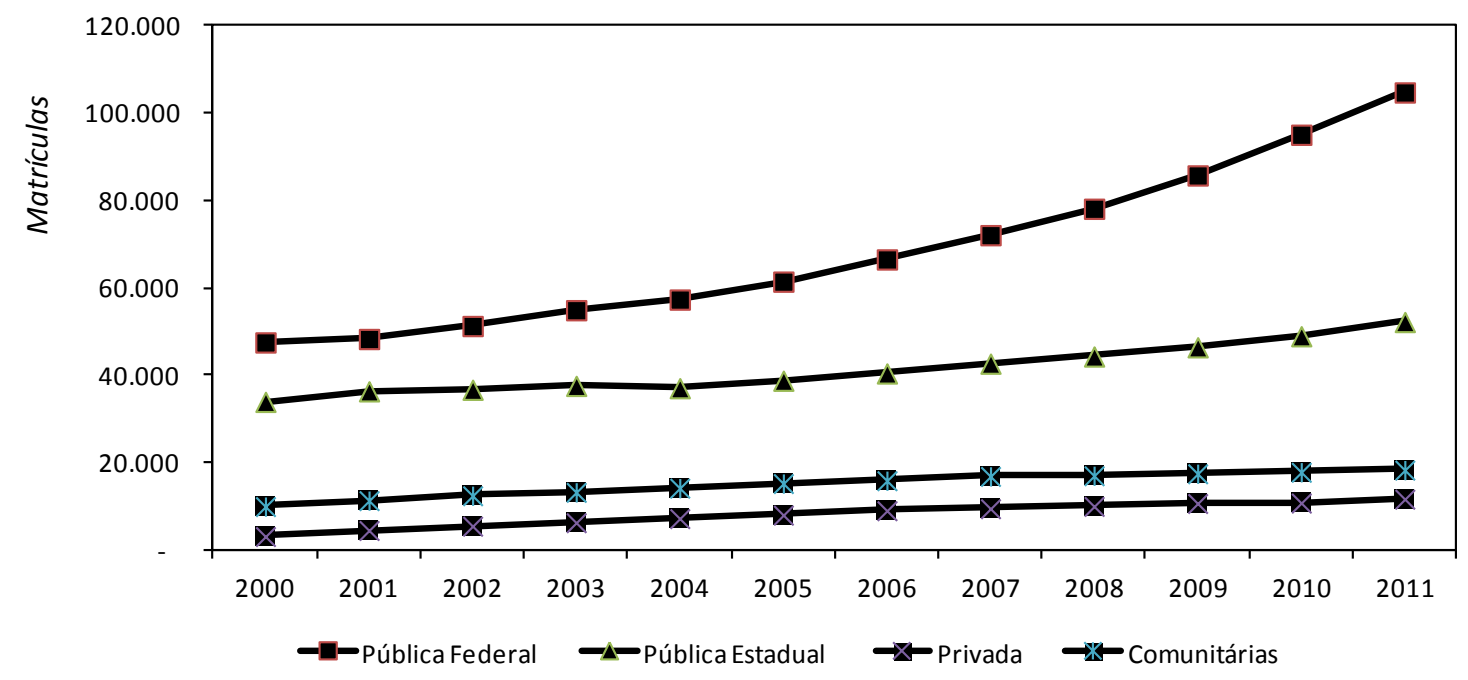

Figura 9. Evolução das matrículas no stricto sensu por categoria administrativa, isolando as IES comunitárias

Fonte: Portal Geocapes, CAPES.

A seção 3 mostrou que 11,7\% das matrículas no ensino superior estão em IES comunitárias. Na pós-graduação stricto sensu, os dados de 2011 (CAPES, 2011), revelam um percentual próximo, 9,7\%, mas que decresce lentamente desde 2005. Os dados de 2011, na Tabela 9, revelam que há 305 programas de pós-graduação em funcionamento em IES comunitárias, dos quais 134 oferecem o nível de doutorado. Esses programas contam com 12.828 matrículas em nível de mestrado e 5.184 no doutorado, tendo realizado 6.176 titulações.

Tabela 9. Distribuição dos Programas de Pós-Graduação stricto sensu de acordo com a categoria administrativa, isolando as comunitárias - 2011

\begin{tabular}{|c|c|c|c|c|c|}
\hline \multirow[t]{2}{*}{ Tipo } & \multirow{2}{*}{$\begin{array}{c}\text { Total de } \\
\text { programas }\end{array}$} & \multicolumn{2}{|c|}{$\begin{array}{c}\text { Mestrado } \\
\text { (Profissional ou Acadêmico) }\end{array}$} & \multicolumn{2}{|c|}{ Doutorado } \\
\hline & & Matrículas & Titulações & Matrículas & Titulações \\
\hline Pública Federal & 1755 & 64.382 & 23.409 & 40.418 & 6.522 \\
\hline Pública Estadual & 733 & 28.434 & 10.281 & 23.768 & 4.436 \\
\hline Comunitárias - ABRUC & 305 & 12.828 & 5.184 & 5.435 & 992 \\
\hline Privada (com ou sem fins lucrativos) & 263 & 9.891 & 3.674 & 1.711 & 263 \\
\hline Pública Municipal & 24 & 838 & 282 & 55 & 4 \\
\hline Totais & 3080 & 116.373 & 42.830 & 71.387 & 12.217 \\
\hline
\end{tabular}

Fonte: Portal Geocapes, CAPES. Dados referentes a 2011.

Para avaliação da qualidade dos programas de pós-graduação stricto sensu oferecidos pelas IES comunitárias, foi utilizado o conceito Capes que varia originalmente numa escala de 1 a 7 (conceito máximo). Apenas programas com 
conceito Capes igual ou superior a 3 foram considerados, já que este é o conceito mínimo para o funcionamento regular de um programa de mestrado. A Tabela 10 apresenta esses resultados com base na avaliação trienal de 2010.

Tabela 10. Distribuição relativa dos conceitos Capes, isolando as comunitárias

\begin{tabular}{lcccccc}
\hline & \multicolumn{5}{c}{ Nota Avaliação Trienal 2010} \\
\cline { 2 - 6 } \multicolumn{1}{c}{ Categoria } & 3 & 4 & 5 & 6 & 7 & Total \\
\cline { 2 - 6 } & $31,80 \%$ & $36,80 \%$ & $20,50 \%$ & $7,10 \%$ & $3,80 \%$ & 1459 \\
Pública Federal & $22,50 \%$ & $30,80 \%$ & $26,60 \%$ & $12,00 \%$ & $8,10 \%$ & 666 \\
Pública Estadual & $34,30 \%$ & $37,40 \%$ & $20,80 \%$ & $6,40 \%$ & $1,10 \%$ & 265 \\
Privada (com ou sem fins lucrativos) & $56,70 \%$ & $30,20 \%$ & $9,80 \%$ & $1,60 \%$ & $1,60 \%$ & 245 \\
Pública Municipal & $70,00 \%$ & $30,00 \%$ & $0,00 \%$ & $0,00 \%$ & $0,00 \%$ & 20 \\
\hline Total & $32,30 \%$ & $34,70 \%$ & $20,90 \%$ & $7,70 \%$ & $4,40 \%$ & 2655 \\
\hline
\end{tabular}

Fonte: Portal Geocapes, CAPES. Dados referentes à Avaliação Trienal 2010.

As IES comunitárias apresentam uma distribuição relativa de conceitos semelhante à categoria pública federal, com $28,30 \%$ dos programas com avaliação igual ou superior a cinco (5). Esse percentual é menor ao obtido por IES públicas estaduais $(46,7 \%)$, mas superior ao das demais IES privadas $(13,0 \%)$. A Figura 10 resume os resultados na forma do conceito Capes médio.

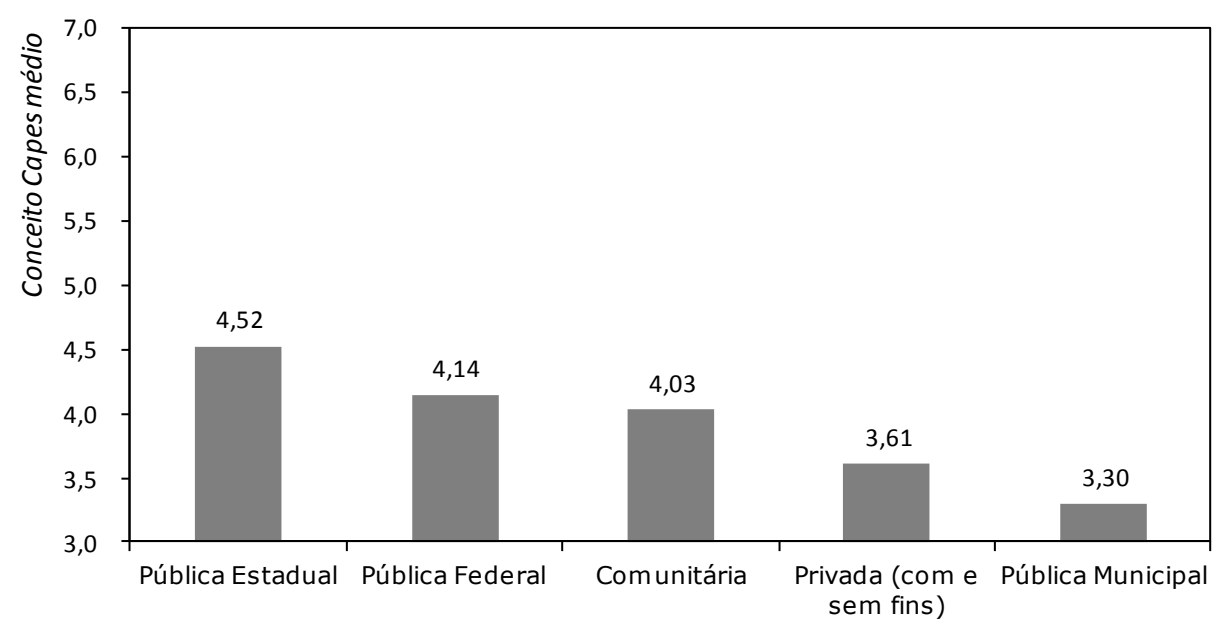

Figura 10. Conceito médio CAPES por categoria administrativa Fonte: Portal Geocapes, CAPES 


\section{Considerações Finais: fragilidades e oportunidades}

A caracterização das universidades denominadas anteriormente comunitárias demonstra que, embora exista uma segmentação das condições de competição no sistema universitário brasileiro, há um desempenho favorável dessas instituições na comparação com as universidades privadas com fins lucrativos, em qualquer dos níveis de formação, além de um desempenho considerado bom na comparação com as universidades públicas. Diferentes instrumentos de avaliação, adotados na graduação ou no sistema de pósgraduação, comprovam um desempenho diferenciado das instituições de ensino superior comunitárias, quando comparadas às instituições particulares, em especial.

A valorização dessas instituições, sobretudo considerada com a promulgação da lei $12.881 / 13$, que operam e contribuem para a consolidação dos cursos superiores no Brasil nesta e em outras fases da história do sistema de ensino superior, além da contribuição ao desenvolvimento local, é justificável à luz das pressões da segmentação presente no sistema universitário.

De um lado, as instituições comunitárias são pressionadas pelas IES públicas quanto à captação de alunos e de profissionais e quanto aos investimentos em pesquisa, a partir de projetos com prazos mais longos. Além disso, as IES privadas com fins lucrativos exercem uma pressão adicional ao oferecer arranjos financeiros atraentes ao segmento de alunos de graduação. A possibilidade de acesso a fundos públicos, sobretudo ampliando a participação em editais de fomento pode transformar a realidade dessas IES, resultando em um incremento de qualidade e ampliando as possibilidades de formação profissional e científica em sua rede, localizada predominantemente no interior.

Ainda assim, até o momento, as universidades sem fins lucrativos constituem-se em centros onde o padrão de qualidade e desempenho tem sido constante e homogêneo, demonstrando diretamente que a organização interna e o acúmulo de experiência dessas instituições são capazes de atender ao nível de exigência desejado pela sociedade brasileira.

O cenário atual da educação superior brasileira propõe desafios à sobrevivência das universidades comunitárias, mas, ao mesmo tempo, acena com oportunidades. A expansão da rede federal de ensino superior gratuito tem absorvido potenciais alunos das IES anteriormente denominadas comunitárias e, além disso, o Sistema de Seleção Unificada (SiSU) permite mobilidade geográfica por meio de um único processo seletivo. Assim, um aluno que reside próximo a uma IES comunitária é um potencial aluno de universidades federais distantes, nas quais dificilmente participaria do processo seletivo nos moldes tradicionais. Por outro lado, o Prouni representa uma importante iniciativa para dinamizar as instituições comunitárias, preenchendo vagas ociosas, criando oportunidades e contribuindo para que a sociedade reconheça e dialogue com as IES comunitárias.

No que concerne ao setor privado, o aumento no número de faculdades, centros universitários e universidades com fins lucrativos cria uma concorrência severa com instituições comunitárias, em especial universidades comprometidas com pesquisa e extensão. Não apenas o aumento do número de instituições, como 
também a maior expansão no número de alunos, resultado de estratégias mais agressivas de captação por parte das instituições particulares contribui para um cenário onde as instituições comunitárias necessitam de uma maior atenção, bem como de um maior reconhecimento.

As universidades comunitárias, pela sua história, consolidação e contribuição à sociedade, além do recente desempenho em termos de excelência poderiam exercer um papel complementar ao das IES públicas, estaduais e federais, sendo possível pensar naquelas como o próximo vetor de expansão de vagas no ensino superior e de inserção dos jovens no mercado de trabalho agregando, a esses, resultados de uma formação em contato com pesquisadores e científica em todos os seus aspectos. Contribuiria para contornar as dificuldades na expansão física de universidades públicas e seria uma importante sinalização para instituições com relevante papel social, que acumularam experiência ao longo de décadas e são pautadas pela busca da excelência.

\section{Referências}

ASSOCIAÇÃO BRASILEIRA DAS UNIVERSIDADES COMUNITÁRIAS - ABRUC. Instituições Filiadas. Disponível em:

http://www.abruc.org.br/sites/500/516/00002160.pdf > . Consulta em agosto de 2012.

BITTAR, Mariluce. Universidade Comunitária: uma identidade em construção. Tese (Doutorado em Educação) - Universidade Federal de São Carlos, UFScar. São Carlos: 1999.

BITTENCOURT, Hélio. R.; CASARTELLI, Alam. O. ; RODRIGUES, Alziro. C. M. Sobre o Índice Geral de Cursos (IGC). Avaliação (Campinas), Sorocaba, v. 14, n. 3, p. 667-682, 2009.

BITTENCOURT, Hélio R.; VIALI, Lorí; RODRIGUES, Alziro. C. M.; CASARTELLI, Alam. O. Mudanças nos pesos do CPC e seu impacto nos resultados de avaliação em universidades federais e privadas. Avaliação (Campinas), Sorocaba, v. 15, n. 3, p. 147-166, 2010.

BRASIL. Decreto Lei n.12.881/13 de 12 de novembro de 2013. Dispõe sobre a definição, qualificação, prerrogativas e finalidades das Instituições Comunitárias de Educação Superior - ICES, disciplina o Termo de Parceria e dá outras providências. Diário Oficial [da República Federativa do Brasil], Brasília, Edição Extra, 13 nov. 2013. Disponível em: http://presrepublica.jusbrasil.com.br/legislacao/112112710/lei-12881-13

CAPES - Coordenação de Aperfeiçoamento de Pessoal de Ensino Superior. Portal Geocapes. Disponível em: http://www.capes.gov.br/component/content/arTicle/44-avaliacao/2961. Consulta em julho de 2012. 
DONOSO DIAZ, Sebastián. A reforma neoliberal na educação superior no Chile em 1981. Revista Brasileira de Ciências Sociais, São Paulo, v. 20, n. 57, p. 53-64, 2005.

GUARESCHI, Elydo Alcides. O processo de construção da Universidade de Passo Fundo. Editora Universitária: Passo Fundo, 2001.

INEP - Instituto Nacional de Estudos e Pesquisas Educacionais Anísio Teixeira. Sinopses Estatísticas da Educação Superior, Brasília, DF, 2000-2011.

INEP - Instituto Nacional de Estudos e Pesquisas Educacionais Anísio Teixeira. Cálculo do Conceito Preliminar de Cursos de Graduação: Nota Técnica. Brasília, DF, 2010a.

INEP - Instituto Nacional de Estudos e Pesquisas Educacionais Anísio Teixeira. Cálculo do Índice Geral de Cursos: Nota Técnica. Brasília, DF, $2010 b$.

MARTINS, André Luiz de Miranda. A marcha do "capitalismo universitário" no Brasil nos anos 1990. Avaliação (Campinas), Sorocaba, v. 13, n. 3, p. 733-743, 2008.

MEC - Ministério da Educação. Sistema e-MEC. Disponível em: < http://emec.mec.gov.br/>. Consulta em Julho de 2012.

MOROSINI, M.; FRANCO, M. E. D. P. Universidades Comunitárias e Sustentabilidade. Educar, Curitiba, n. 28, p. 55-70, 2006.

PINTO, Maira Meira. Responsabilidade social e universidade comunitária: novos rumos para a educação superior. Tese (Doutorado em Educação) - Faculdade de Educação, PUCRS. Porto Alegre: 2009

PNUD - Programa das Nações Unidas para o Desenvolvimento. Atlas do Desenvolvimento Humano - Municípios 2003. Brasília: PNUD, 2003. Disponível em: $<$

http://www.pnud.org.br/IDH/Atlas2003.aspx?indiceAccordion=1\&li=li_Atlas200 3>. Consulta em agosto de 2012.

RISTOFF, Dilvo; GIOLO, Jaime. O Sinaes como Sistema. Revista Brasileira da PósGraduação (RBPG), v. 3, n. 6, p. 193-213, 2006.

SANTOS, Poliana. Dilma: faculdade comunitária interioriza ensino superior. O Estado de São Paulo. 27 de novembro de 2013. Disponível em: http://www.estadao.com.br/noticias/geral,dilma-faculdade-comunitariainterioriza-ensino-superior, 1101413,0.htm

SCHMIDT, João Pedro. O comunitário em tempos de público não estatal. Avaliação (Campinas), Sorocaba, v. 15, n. 1, p. 9-39, 2010. 
THOMÉ, Vilmar; LOURENÇO, Marcelo F.; SCHMIDT, João P.; ROHR, Christian. As Instituições Comunitárias de Educação Superior: síntese de informações com base no censo da educação superior 2009. Brasília: ABRUC, 2011. Disponível em:

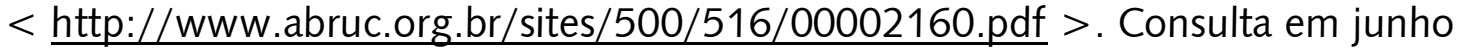
de 2012.

TRINDADE, Hélgio. Reforma universitaria en Brasil: el desafío del gobierno de Lula. Espacio Aberto, Maracaibo, v. 16, n. 1, p. 31-60, 2007.

VANNUCCHI, Aldo. A universidade comunitária o que é como se faz. Editora Loyola, São Paulo: 2004.

Submetido em

Aprovado em

\section{Sobre os autores}

Hélio Radke Bittencourt

Doutor em Geografia pela Universidade Federal do Rio Grande do Sul (UFRGS), Professor do Departamento de Estatística, Faculdade de Matemática - Pontifícia Universidade Católica do Rio Grande do Sul (PUCRS).

Endereço: Av. Ipiranga, 6681, Bairro Partenon. Porto Alegre, RS - Brasil. CEP: 90619-900.

E-mail: heliorb@pucrs.br

\section{Alziro César de Morais Rodrigues}

Doutor em Administração pela École des Hautes Études Commerciales (França). Assessor da Reitoria. Professor da Faculdade de Administração, Contabilidade e Economia - PUCRS.

Endereço: Av. Ipiranga, 6681, Bairro Partenon. Porto Alegre, RS - Brasil. CEP: 90619-900.

E-mail: rodrigues@pucrs.br

\section{Alam de Oliveira Casartelli}

Doutor em Comunicação Social pela PUCRS. Relator da Comissão Própria de Avaliação. Professor da Faculdade de Administração, Contabilidade e Economia e do Programa de Pós-graduação em Educação - PUCRS.

Endereço: Av. Ipiranga, 6681, Bairro Partenon. Porto Alegre, RS - Brasil. CEP: 90619-900.

E-mail: alam@pucrs.br

\section{Gustavo Inácio de Moraes}

Doutor em Economia pela USP. Professor da Faculdade de Administração, Contabilidade e Economia e do Programa de Pós-Graduação em Economia da PUCRS.

Endereço: Av. Ipiranga, 6681, Bairro Partenon. Porto Alegre, RS - Brasil. CEP: 90619-900.

E-mail: gustavo.moraes@pucrs.br

Gabriela Ludwig Guerra

Acadêmica do curso de Administração de Empresas. Ex-bolsista de Iniciação Científica BPA/PUCRS. 